\title{
COMPLIANCE OF IRON SUPPLEMENTATION DURING PREGNANCY AND FACTORS EFFECTING COMPLIANCE.
}

1. MBBS, DMRT

Assistant Professor Department of Radiotherapy \&

Nuclear Medicine Sargodha Medical College, Sargodha.

2. MBBS, FCPS (Medicine)

Assistant Professor

Department of Medicine DHQ Teaching Hospital, Sargodha medical College, Sargodha.

3. MBBS, FCPS (Surgery)

Associate Professor Department of Surgery Bolan Medical College, Quetta.

4. MBBS, FCPS (Surgery) Assistant Professor

Department of Surgery DHQ Teaching Hospital, Sargodha Medical College, Sargodha.

5. Pharm-D, M.Phil (Pharmaceutics) College of Pharmacy, University of Sargodha, Sargodha

6. Pharm-D, M.Phil (Pharmaceutics) College of Pharmacy,

University of Sargodha, Sargodha.

Correspondence Address:

Dr. Haroon-ur-Rashid

Department of Radiotherapy and

Nuclear Medicine,

Sargodha Medical College,

University of Sargodha, Sargodha

drharoonkhan@hotmail.com

Article received on:

25/02/2019

Accepted for publication:

$15 / 08 / 2019$

\section{INTRODUCTION}

Iron is an essential element and required for the appropriate functioning of hemoglobin. It is involved in oxygen transport, cytochromes, the mitochondrial electron transport chain and cellular metabolism. It is involved in important functions with catalases and peroxidases involved in redox reactions. Metallo-proteins also contain iron which is essential for DNA synthesis, steroid and hormones synthesis, cell proliferation, gene regulation and differentiation, neutrophil respiratory burst of phagocytosis and drug metabolism. ${ }^{1}$

In the same way, in pregnant women demand for iron increase evenly throughout gestation. The need for iron varies considerable during
Haroon ur Rashid1, Sheraz Saleem², Khan Muhammad Babar ${ }^{3}$, Khalid Mahmood ${ }^{4}$, Hina Younis ${ }^{5}$, Safirah Maheen ${ }^{6}$

STCT... Objectives: This study aims at measuring compliance to iron supplements therapy is a major problem due to possible side effects and long-term duration of therapy study Design: Retrospective questionnaire-based study. Setting: Mola Bakhsh Hospitals, Sargodha, females were recruited in study. Data was collected through a questionnaire translated in local language. On this basis sample population was divided into three groups compliant, partially compliant and non-compliant major factors associated with the prevalence of anemia and non, was found that iron deficiency anemia is prevalent in about $64 \%$ of females in the third trimester. Improvement in $\mathrm{Hb}$ level in third trimester compared to $1^{\text {st }}$ trimester was taken as parameter imparting nutritional education with special emphasis to improve dietary intake of proteins and Key words: $\quad$ Anemia, Compliance, Hemoglobin, Iron Supplements, Pregnancy.

Article Citation: Haroon ur Rashid, Saleem S, Babar KM, Mahmood K, Younis H, Maheen $\mathrm{S}$. Compliance of Iron Supplementation during pregnancy and factors effecting compliance. Professional Med J 2019; 26(12):2128-2134. DOI: 10.29309/TPMJ/2019.26.12.3318 
takes an iron containing diet, a pre-pregnancy iron store of $300 \mathrm{mg}$ may be enough to carry her pregnancy, If the diet contains less iron than optimal value than more iron store is needed. ${ }^{4}$

\section{The World Health Organization (WHO)} recommends that hemoglobin $(\mathrm{Hb})$ preferably should be maintained at or above $11.0 \mathrm{~g} / \mathrm{dl}$, and it should not be allowed to decrease below $10.5 \mathrm{~g} /$ dl during second trimester of pregnancy. ${ }^{5}$

In pregnancy anemia is one of the most serious health problems for both mother and child. It is associated with heart failure, reduced immune response, intrauterine growth retardation and maternal and perinatal mortality. Half of the pregnant women in developing countries are effected by anemia. There are many factors which cause anemia in pregnancy, the main causes are hemorrhage, nutritional deficiencies, infestations, infections, malaria, AIDS/ HIV infections, hemoglobinathies, sickle cell disease, and intestinal parasitosis. ${ }^{6}$

According to Health Survey and Pakistan Demographics 2006-07, maternal mortality was revealed to be high with 276 deaths per 100,000 live births as compare to 1 in 8,000 in the developed countries. Among 89 Pakistani women one dies due to the complications of child birth. ${ }^{7}$

Strategies to prevent anemia in pregnancy in developing countries usually focus on iron and folic acid supplementation in antenatal care, malaria chemoprophylaxis and also anthelminthic treatment may have beneficial results. Main problem with iron supplementation during pregnancy is compliance, due to various factors women often fail to take the iron supplements regularly as advised by their health care professionals and leads towards high prevalence of anemia in pregnant mothers. This reveals the importance and need to study the factors which effect compliance of iron supplements. ${ }^{9}$

Therefore, the objectives of the study were to

1. Determination of frequency of iron deficiency anemia in pregnant females in Sample Population of Sargodha district.
2. To correlate the level of compliance and adherence to the iron supplements and its influence over the hemoglobin levels of the pregnant women.

3. Major factors affecting compliance.

\section{METHODOLOGY}

A retrospective cohort study conducted in Mola Baksh Hospital in which total 267 pregnant women took part that were in first and third trimester of pregnancy. Exclusion criteria followed women that were in $2^{\text {nd }}$ trimester and those having pregnancy or other hematological complications. Study defined compliance as the adherence of pregnant women the practice of taking of iron supplements on daily basis. Lab findings of Hemoglobin level were compared with standard value Hemoglobin level byWHO. ${ }^{8}$

Collection of data from the respective subjects was carried out with the help of an interview based questionnaire consisted of variables such as socio-demographic parameters, knowledge about anemia, prevalence of anemia and factor affecting compliance. Assessment totally relied upon the response of subjects to the questionnaire and depiction of results was carried out in the form of tables and graphs. Prevalence of anemia among the subjects was categorized as 1 . Anemic in $1^{\text {st }}$ trimester; 2 . Anemic in $3^{\text {rd }}$ trimester; 3. Non-anemic in $1^{\text {st }}$ trimester; 4 . Non-anemic in in $3^{\text {rd }}$ trimester. In the results the assessment of supplementation compliance was categorized into one of the three groups i.e. partially compliant, Compliant and Non-compliant.

\section{RESULTS AND DISCUSSIONS}

The main results from the analysis were presented in tables and graphs given below.

\section{Subject Demographic Data}

A total of 267 pregnant females form Mola Bakhsh Hospital Sargodha took part in study. All of the participating females were in the $1^{\text {st }}$ and $3^{\text {rd }}$ trimester. With respect to age the population was divided into three groups, group 1 includes patients with less than 25 years of age including $25.46 \%$ of sample population, group 2 patients with 25-35 years of age include $52.80 \%$ and 
group 3 subjects with age greater than 35 years includes $21.72 \%$ of the population.

$11.98 \%$ of the subjects were found to be educated higher than intermediate while most of the population $58.05 \%$ was under intermediate and $29.96 \%$ were found to be under primary or illiterate. Only 30 out of 267 females were found to be working in different professional fields while most of the females i.e. $88.76 \%$ said that they are house wives. A detailed review of patient demographic data is shown in Table-I.

Various parameters were studied in population to determine the cause of anemia in pregnancy and non-compliance to iron supplements. After the adjustment of other factors one factor shown to have a significant association with the compliance was age. In this study $25.46 \%$ of population was under 25 years of age out of which $64.7 \%$ was found anemic.

Women having more than 25 years of age were more compliant to iron supplements than women with younger age ( $<25$ years). Elder women may have more concern for their health and pregnancy outcomes as having more experiences in the prevention and treatment of Iron Deficiency Anemia (IDA). This judgment was parallel to the study of P. Mithra in India that elderly and middle women were slightly more compliant than younger women (P. Mithra 2013) and also this finding is consistent with the study done in Ethiopia. ${ }^{10}$

Next factor which effect compliance is Education, it was seen that the women which were more educated had more concern about their health and compliant to iron supplementation therapy as compare to illiterate women. Family Income also plays important role in compliance, the women which belongs to low income families were less compliant to iron supplement therapy as compare to women which belongs to rich families, the possible reason for this may be affordability of supplements.

Out of 267 females $60.67 \%$ were found anemic throughout the pregnancy that indicates the prevalence of anemia in Sample population. The
World Health Organization estimates that 58\% of pregnant women in low-income countries are anemic. ${ }^{2}$ None of the sample population was found to be suffering from any chronic disease. Data reveals that $78.27 \%$ of patient population visit antenatal clinic regularly. $64.04 \%$ of total patient population were found to be anemic at the end of their $3^{\text {rd }}$ trimester, $39.32 \%$ of population show fluctuating $\mathrm{Hb}$ during their pregnancy. None of the female was found to be suffering from any pregnancy related complication like pre-eclampsia, gestational diabetes mellitus, oligohydramnios, intrauterine growth retardation etc. Iron deficiency anemia (IDA) is one of the common nutritional deficiencies worldwide, which a $\square$ ects over two billion people worldwide according to World Health Organization. ${ }^{3}$

A detailed review of all the results relating prevalence of anemia in pregnant females is shown in Table-II

\section{Factor affecting compliance in sample population}

Based on $\mathrm{Hb}$ status most of the population $86.51 \%$ was advised to use iron folate supplements throughout their pregnancy based on their $\mathrm{Hb}$ status either OD (66.29\%), BD $(30.71 \%)$ or TID $(2.9 \%)$ therapy. Out of sample population $68.39 \%$ of subjects complains of having side effects due to iron supplements during pregnancy most common observed side effects were nausea vomiting (68.39\%), diarrhea, constipation $(40.50 \%)$, heart burn $(21.51 \%)$ etc which sometime or very often leads to stop iron supplement therapy.

The side effect is repetitively considered as main problem affecting compliance. According to studies of Anil Bilimale et al, (2010) conducted in the side effects was reason for skipping doses of iron supplements among pregnant women by $27.0 \%, 20.2 \%$, and $27.6 \%$, respectively. Similar studies were completed in eight districts of four regions of Ethiopia and Amhara, an area of Ethiopia exposed that $63.3 \%$ and $54.4 \%$ of respondents respectively, missed iron supplement doses due to side effectsfear. ${ }^{10}$ 
One possible reason for non-compliance related to side effects in study may be due to lack of information about side effects in advance. Proper counseling can increase the psychological acceptance of pregnant women towards side effects of iron supplements. ${ }^{11}$

Patient knowledge about iron supplements and anemia was also considered, only $38.20 \%$ of population answer "yes" to question what is anemia. While $61.79 \%$ females do not know anything about anemia. More over $18.35 \%$ population complained of financial issue (low income) or nutritional status as a cause of their anemia.

This contradiction may be due to insufficient counseling of pregnant mothers and it could be improved through better counseling during the ANC visit by suggesting to women strategies to remember to take their tablets, for example, placing the tablets in a spot that they see every day Because of consumption iron supplements there was fear of having big fetus in women which was obstruction to compliance with iron supplementation study done in Thailand. ${ }^{12}$ But, in current study, none reported stopping of iron supplement therapy because of terror of having over weight fetus.

This may be due to differences in location of study subjects. Women who visited ANC regularly were more compliant to iron supplements as compared to women who did not visited or rarely visited ANC. These findings were similar with findings inPhilippines. ${ }^{14}$

The most probable reason for this is that health professionals may guide women during their visits to ANC by discussing benefits of compliance and encourage them to take as prescribed dosage of supplements which assist mothers to be compliant. In current study, pregnant mothers which had good information about anemia were more compliant with iron supplement during pregnancy as compared to women who had poor understanding about anemia. These results were consistent with study in Vientiane, Nigeria, and Amhara region of Ethiopia. ${ }^{15}$
Knowledge may create good awareness to prevent and treat anemia during pregnancy by taking iron supplement regularly. These finding were consistent with the results of study completed in India (Haryana state), Cambodia, Sweden and Senegal. ${ }^{16}$

Another main cause of non-compliance was forgetfulness, $64 \%$ of sample population said that they frequently or sometime not remember to take the iron-folate supplements and this result is closer with the conclusion in Vientiane and India by $47.9 \%$ and $48.8 \%$, respectively (S. Jasti 2007 ,P. Vongvichit 2003), but it is much more than the results in Ethiopia that was $16.7 \% .^{13}$

\section{Relative Compliance Report}

After a thorough analysis of above data sample population was divided into three groups as compliant, partially compliant and non-compliant.

Women taking their medicines regularly having improving $\mathrm{Hb}$ status, and less anemic in $3^{\text {rd }}$ trimester as compare to anemia in $1^{\text {st }}$ trimester and these were placed in compliant group. While those who were not taking there iron supplements were without any improvement in $\mathrm{Hb}$ status and considered as non-compliant and those with fluctuating $\mathrm{Hb}$, were named as partially compliant as shown in Figure-1.

The result revealed that $56.17 \%$ of pregnant mothers were compliant to the supplement, which is lower as compared with the study completed in regions of Ethiopia which was $74.9 \%{ }^{13}$ much higher than study completed in Amhara regions of Ethiopia which was $20.4 \%$ (B. Taye 2015).

The probable reason for this difference may be due to the time gap between studies, subjects and geographic locations.

\section{Comparison of different factors effecting compliance}

A comparion of different factors associated with non compliance to iron supplementaion and anemia is shown in Figure-2. 


\begin{tabular}{|c|c|c|c|}
\hline Parameters & Categories & No. of Subjects & Percentage (\%) \\
\hline \multirow{3}{*}{ Age (years) } & $<25$ & 68 & 25.46 \\
\hline & $25-35$ & 141 & 52.80 \\
\hline & $35-45$ & 58 & 21.72 \\
\hline \multirow{3}{*}{ Education } & Primary/illiterate & 80 & 29.96 \\
\hline & Intermediate & 155 & 58.05 \\
\hline & University & 32 & 11.98 \\
\hline \multirow{2}{*}{ Work Status } & House wife & 237 & 88.76 \\
\hline & Working & 30 & 11.23 \\
\hline \multirow{3}{*}{ Family income } & Low & 49 & 18.35 \\
\hline & Moderate & 180 & 67.41 \\
\hline & High & 38 & 14.23 \\
\hline \multirow{3}{*}{ No. of live Children } & None (primiparous) & 36 & 13.48 \\
\hline & $1-3$ & 185 & 69.28 \\
\hline & $>3$ & 46 & 17.22 \\
\hline \multicolumn{4}{|c|}{ Table-I. Demographic characteristics of studied samples } \\
\hline & & Patient population & Percentage \\
\hline \multirow{2}{*}{ Anemic } & $1^{\text {st }}$ trimester & 87 & $32.58 \%$ \\
\hline & $3^{\text {rd }}$ trimester & 75 & $28.08 \%$ \\
\hline \multirow{2}{*}{ Non-anemic } & $1^{\text {st }}$ trimester & 47 & $17.60 \%$ \\
\hline & $3^{\text {rd }}$ trimester & 58 & $21.72 \%$ \\
\hline Anemic throughout & & 162 & $60.67 \%$ \\
\hline Fluctuating $\mathrm{Hb}$ & & 105 & $39.32 \%$ \\
\hline
\end{tabular}

Table-II. Prevalence of anemia in sample population

\begin{tabular}{|c|c|c|c|}
\hline Parameters & & Patient Population & Percentage (\%) \\
\hline \multirow{2}{*}{ Regular Antenatal visit (out of 267) } & Yes & 209 & 78.27 \\
\hline & No & 58 & 21.72 \\
\hline \multirow{2}{*}{ Recommended iron supplements (out of 267) } & Yes & 231 & 86.51 \\
\hline & No & 36 & 13.49 \\
\hline \multirow{2}{*}{ Reported side effects (out of 231) } & Yes & 158 & 68.39 \\
\hline & No & 73 & 31.39 \\
\hline \multirow{3}{*}{ Stoppage of therapy due to side effects (out of 158) } & Never & 60 & 37.39 \\
\hline & sometime & 64 & 40.50 \\
\hline & Often & 34 & 21.51 \\
\hline \multirow{3}{*}{ Iron supplement regimen (out of 267) } & OD & 177 & 66.29 \\
\hline & BD & 82 & 30.71 \\
\hline & TID & 8 & 2.99 \\
\hline \multirow{3}{*}{ Forgetfulness (out of 267) } & Never & 97 & 36.32 \\
\hline & Sometime & 86 & 32.20 \\
\hline & often & 84 & 31.46 \\
\hline \multirow{2}{*}{ Knowledge relating anemia (out of 267 ) } & Yes & 102 & 38.20 \\
\hline & No & 165 & 61.79 \\
\hline
\end{tabular}




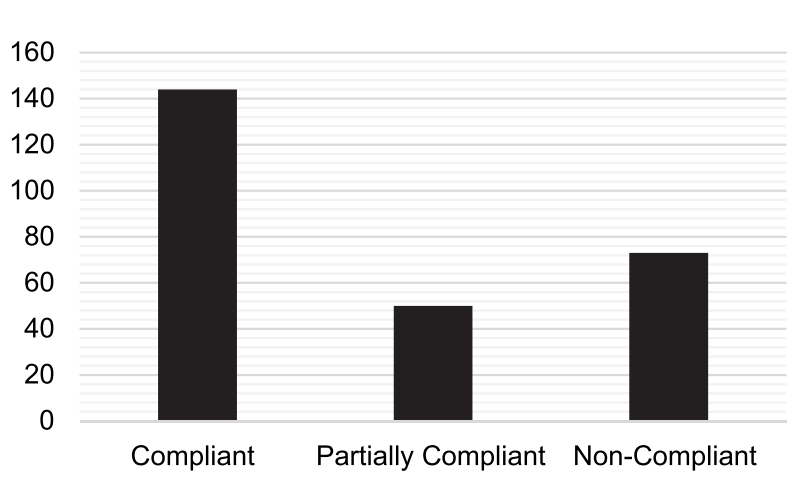

Figure-1. Relative compliance report among studied population

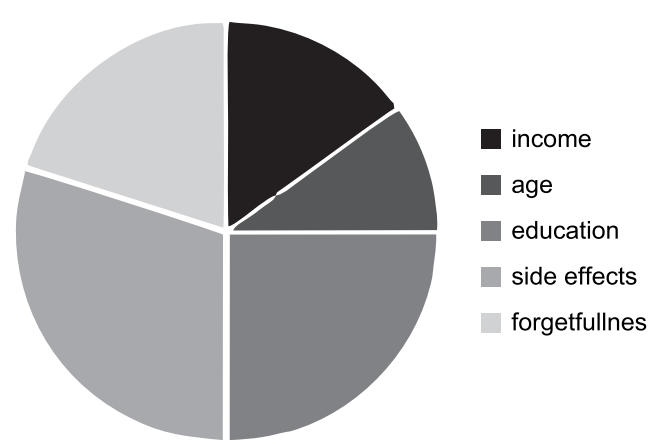

Figure-2. Comparative depiction of different factors affecting compliance

\section{CONCLUSION}

Nutritional or iron deficiency anemia during pregnancy continues to be a major health problem all over the world and iron supplements are used worldwide to tackle this problem. Unfortunately, side effects due these iron supplements and certain human habits act as hurdle to fight anemia during pregnancy To eradicate these hurdles certain steps need to be taken at individual and community level like education of the women as regards anemia, its causes and health implication. Imparting nutritional education, with special emphasis on strategies based on locally available food stuffs to improve the dietary intake of proteins and iron, administration of appropriate iron supplements and ensuring maximum compliance, universal antenatal care to pregnant women will help in combating this serious problem. Long term policies by government, non-government agencies and the community can be directed to formulate effective plans like eradicating anemia in pregnant women and adolescent girls.
Copyright@ 15 Aug, 2019.

\section{REFERENCES}

1. Coad J, Pedley K. Iron deficiency and iron deficiency anemia in women. Scandinavian journal of clinical and laboratory investigation. 2014:74:sup244, 82-89, DOI: 10.3109/00365513.2014.936694

2. Bothwell $\mathrm{TH}$. Iron requirements in pregnancy and strategies to meet them. The American journal of clinical nutrition. 2000 Jul 1;72(1):257S-64S.

3. World Health Organization. Prevention and management of severe anemia in pregnancy. Report of a Technical Working Group, Geneva, 20-22 May 1991. Maternal Health and Safe Motherhood Programme, Geneva: WHO.

4. Saeed Akhtar PhD, Anwaar Ahmed PhD, Asif Ahmad PhD, Zulfiqar Ali PhD, Muhammad Riaz PhD, Tariq Ismail MSc. (2013). Iron status of the Pakistani populationcurrent issues and strategies. - Asia Pac $\mathrm{J}$ Clin Nutr; 22 (3):340-347.

5. Fairbanks VF. Iron in medicine and nutrition. Modern nutrition in health and disease. 1994.

6. Jamel A Haider, Rebecca S Pobocik (2009). Iron deficiency anemia is not a rare problem among women of reproductive ages in ethiopia; A community based cross sectional study. BMC Blood Disorders 2009, 9-7.

7. Svanberg B. Iron absorption in early pregnancy-a study of the absorption of non-haeme iron and ferrous iron in early pregnancy. Acta Obstetricia et Gynecologica Scandinavica. 1975 Jan;54(S48):69-85.

8. World Health Organization Micronutrient deficiencies. Iron deficiency anemia. (2011) www.who. int.

9. Siddiqui MS. Siddiqui KS. Public health significance of iron deficiency Anaemia. Pak Armed Forces Med J. 2008: 58: 319-30.

10. Godara S, Hooda R, Nanda S, Mann S. To study compliance of antenatal women in relation to iron supplementation in routine ante-natal clinic at a tertiary health care centre. Journal of Drug Delivery and Therapeutics. 2013 May 13;3(3):71-5. 
11. Rae Gallowaya, Erin Duschb, Leslie Elderc, Endang Achadid, Ruben Grajedae, Elena Hurtadoe, Mike Favinf, Shubhada Kananig, Julie Marsabanh, Nicolas Medai, K. Mona Mooref, Linda. Morisonj, NeenaRainak, Jolly Rajaratnaml, Javier Rodriquezm, Chitra Stephenn (2002). Women's perceptions of iron deficiency and anemia prevention and control in eight developing countries. -Social Science \& Medicine 55, 529-544.

12. Bilimale A, Anjum J, Sangolli HN, Mallapur M. Improving adherence to oral iron supplementation during pregnancy. Australasian Medical Journal (Online). 2010 Apr 15(5):281.

13. Gebremedhin S, Samuel A, Mamo G, Moges T, Assefa T. Coverage, compliance and factors associated with utilization of iron supplementation during pregnancy in eight rural districts of Ethiopia: a cross-sectional study. BMC public Health. 2014 Dec;14(1):607.

14. Hyder SZ, Persson LÅ, Chowdhury AM, Ekström EC. Do side-effects reduce compliance to iron supplementation? A study of daily-and weekly-dose regimens in pregnancy. Journal of Health, Population and Nutrition. 2002 Jun 1:175-9.
15. Lutsey PL, Dawe D, Villate E, Valencia S, Lopez O. Iron supplementation compliance among pregnant women in Bicol, Philippines. Public health nutrition. 2008 Jan;11(1):76-82.

16. Taye B, Abeje G, Mekonen A. Factors associated with compliance of prenatal iron folate supplementation among women in Mecha district, Western Amhara: a cross-sectional study. Pan African Medical Journal. $2015 ; 20(1)$.

17. Lacerte $\mathrm{P}$, Pradipasen $\mathrm{M}$, Temcharoen $\mathrm{P}$, Imamee $\mathrm{N}$, Vorapongsathorn T. Determinants of adherence to iron/folate supplementation during pregnancy in two provinces in Cambodia. Asia Pacific Journal of Public Health. 2011 May;23(3):315-23.

\begin{tabular}{|c|c|c|c|}
\hline \multicolumn{4}{|c|}{ AUTHORSHIP AND CONTRIBUTION DECLARATION } \\
\hline Sr. \# & Author(s) Full Name & Contribution to the paper & Author(s) Signature \\
\hline 1 & Haroon ur Rashid & $\begin{array}{l}\text { Manuscript proof reading } \\
\text { and submission. }\end{array}$ & \\
\hline 3 & Khan Muhammad Babar & Conception of idea. & \\
\hline 4 & Khalid Mahmood & Questionnaire designing. & \\
\hline 5 & Hina Younis & Data collection. & \\
\hline 6 & Safirah Maheen & $\begin{array}{l}\text { Interpretation \& } \\
\text { compilation of results. }\end{array}$ & h \\
\hline
\end{tabular}

